\title{
Progress requires scientific thinking at all levels
}

\section{This underpins the core values of a moderate society and must not be limited to an élite.}

Sir - As a medical student and a Pakistani, I was encouraged to read the Commentary by Atta-ur-Rahman and Anwar Nasim, "Time for 'enlightened moderation'” (Nature 432, 273; 2004). Students would be the first to benefit from the development of a scientific culture across the Islamic world. On the other hand, increasing spending on higher scientific education (by funding PhDs and establishing research centres, as the authors suggest) would not be an effective way to develop a moderate, mature and tolerant Islamic society.

Instead of offering narrow solutions that largely benefit those within the scientific community, we would do better to encourage scientific thinking across all segments of society, so that intellectual rigour and openmindedness become core social values.

Scientific thinking is characterized by scepticism, objectivity, an appreciation of uncertainty and the flexibility to alter one's beliefs in the face of conclusive evidence. Within the scientific community, these values stimulate open debate and ensure rigorous analysis of data and hypotheses.

However, if public interest in science is underdeveloped and the values underlying scientific thinking remain alien to large portions of the populace, scientists will be unable to effect any real change in social attitudes.
To develop a moderate, enlightened society, the values that underpin scientific thinking should be cultivated among secondary-school students, by improving the quality and availability of scientific education for everyone.

I do not doubt the importance of an active, productive scientific community for the intellectual and economic wellbeing of a nation. But I do not believe that expending resources to advance the scientific education of a few will bring enlightenment to a whole society.

Sheheryar Kabraji

Wolfson College, Barton Road,

Cambridge CB3 9BB, UK

\section{Meyer paper: don't hang the Soc. Wash. out to dry}

Sir - As a systematist I was dismayed to read Vladimir Svetlov's comments in Correspondence (Nature 431, 897; 2004). Svetlov addresses the unfortunate publication of S. C. Meyer's 'intelligent design' (ID) paper (Proc. Biol. Soc. Wash. 117, 213-239; 2004). However, instead of directing criticism at that paper, he makes scathing claims about low-impact journals in general and the Proceedings in particular.

Svetlov describes the Proceedings as a journal that "enjoyed much-deserved obscurity". This characterization is not accurate. A cursory review of authorship in the Proceedings throughout its 122-year history reveals a list of everyone who's anyone among systematic biologists, including scores of notable past and current scientists from the Smithsonian Institution.

Journals that primarily publish taxonomic descriptions (such as the Proceedings) generally have low impact factors, but the relevance of such papers is often long-lasting relative to those in highimpact journals, as they are cited across decades and centuries rather than over a period of a few years (a search of Nature's website shows that Proceedings articles have been cited in at least three Letters to Nature since 2002). Such papers are hardly "inconsequential".

Svetlov says: "The editors and reviewers of many low-impact journals cannot provide the quality reviewing process one gets with Nature, Science, Cell and a few (very few indeed) other established magazines." My own experience is that a journal's impact factor does not reflect the quality of the review process per se. Submissions to low-impact periodicals are often reviewed by sticklers who examine mundane conclusions with the same caution that a reviewer for Nature would use in evaluating more grandiose scientific claims. Indeed, the same experts commonly evaluate papers in both high-impact journals such as Nature and low-impact specialist journals. This is why Svetlov should perhaps not be "surprised it took so long” for a paper such as Meyer's to appear in the peer-reviewed literature.

Given the Proceedings' taxonomic focus, Meyer's ID paper is clearly out of place. Its publication represents a lapse of the journal's usual editorial policies, and has been swiftly repudiated (www. biolsocwash.org). However, although the publication of Meyer's paper is lamentable, it need not be used to trivialize the Proceedings' long, respectable and ongoing tradition of cataloguing global biodiversity. Kristofer M. Helgen

School of Earth and Environmental Sciences, University of Adelaide, Adelaide, SA 5005, Australia, and South Australian Museum, North Terrace, Adelaide, SA 5000, Australia

\section{Meyer publication worse than just bad science}

Sir — Vladimir Svetlov makes some interesting points, in Correspondence, about the proliferation of peer-reviewed journals and the publication of flawed papers (Nature 431, 897; 2004). But he does not take the recent publication of an 'intelligent design' (ID) paper (Nature 431, 114 ; 2004) seriously enough.

We agree that the paper presented no new arguments and appeared in a relatively obscure journal. For such reasons it is unlikely to influence scientists. However, this does little to diminish its usefulness to ID proponents, who wish to influence public rather than scientific opinion.

The point is that, before it was withdrawn, this 'peer-reviewed publication' could be used by ID supporters in the United States to lend apparent legitimacy to their efforts to convince legislators and state and local education boards that ID is science and should be taught alongside darwinian evolution in public schools.

Such efforts are, alarmingly, bearing fruit in many US states - including Ohio (see www.ncseweb.org/resources/news/ 2004/OH/832_critical_analysis_of_ evolutio_3_10_2004.asp), where Svetlov himself is currently based.

Day B. Ligon, Matthew B. Lovern Department of Zoology, Oklahoma State University, 430 Life Sciences West, Stillwater, Oklahoma 74074, USA

\section{Let's see what happens if I press this button...}

Sir - I simply cannot free my mind of the marvellous dreamscape inspired by the Correspondence letter "US rules on tech transfer to foreign nationals" from Peter Lichtenbaum of the US Department of Commerce (Nature 432, 15; 2004).

I, the humble foreign-national visitor, enter the generous host laboratory and start twiddling the knobs on their latest \$1-million gizmo, perhaps with disastrous results for its integrity.

But the resident expert technician cannot approach me with advice because that's 'training', and requires a licence! Robin Thompson Five Halls, Little Bookham Common, Surrey KT23 3HY, UK 